borne illness during the period that Sydney will host the Games.

Operation Foodwatch is a program of enhanced food hygiene surveillance for food premises in the public domain. Local Councils and Public Health Units throughout greater Metropolitan Sydney report to a centrally-located database, which has been operating since early 1999. The information gathered by this system is used to categorise food premises, based on inspection histories. This information is used to target high risk outlets for more intensive inspection and follow up.

\section{THE SYDNEY 2000 OLYMPIC GAMES PLAN}

The Food Safety Strategy for Olympic venues involves the following actions:

- specification of special food hygiene conditions in SOCOG contracts and the highlighting of statutory obligations (for example, contractual obligations placed on Olympic venue caterers include the requirements that Hazard Analysis and Critical Control Point, or HACCP, Food Safety Plans be in place); ${ }^{2}$

- identification of all contracted food operations located within Olympic venues;

- allocation of a broad food safety risk rating (high, medium or low risk) to each food service outlet, according to whether they are serving potentially hazardous food types;

- coordination of ongoing site inspections and hygiene compliance checks and audits at all venues;

- recording of all food safety surveillance activities and central collation of data including daily summary reporting;

- implementation of the Strategy at test events prior to the Games to trial the inspection process and, if necessary, refine and enhance it.
Some of the key tasks in monitoring venue-based food operations will include:

- ongoing inspections of food premises and outlets to ensure compliance with food hygiene standards

- routine inspection of delivery and distribution vehicles

- selective sampling and testing of foods

- investigation of complaints received from the general public

- active surveillance for food-borne disease outbreaks.

\section{FOOD SAFETY WORKFORCE}

The Olympic food safety workforce will be drawn from both local government and NSW Health. Food safety surveillance personnel will implement the actions identified in the Food Safety Strategy for the 15 venues located within Sydney Olympic Park. Local government officers and food inspectors from area health service public health units will carry out food surveillance work in the 14 competition venues within the Sydney East, Darling Harbour and Sydney West Olympic Precincts. This workforce will operate during the pre-Olympic, Olympic and Paralympic periods in September and October 2000.

The detailed planning underpinning the Olympic Food Safety Strategy, and the strong collaborative approach between NSW Health and Local Government in implementing it, should minimise food-borne illnesses during the Games.

\section{REFERENCES}

1. Maria Visotina. Health and Medical Services for the Centennial Olympic Games Atlanta Georgia. Unpublished Report. Sydney: NSW Department of Health, 1996.

2. Codex Alimentarius Commission. Joint WHO-FAO Hazard Analysis and Critical Control Point System for food safety, 1993.

3. The Food Safety Strategy for the Sydney 2000 Olympic and Paralympic Games. Sydney: NSW Department of Health, 2000.

\title{
COORDINATING PUBLIC HEALTH SERVICES AT OLYMPIC VENUES DURING THE SYDNEY 2000 OLYMPIC AND PARALYMPIC GAMES
}

\section{Sarah Thackway}

Surveillance Manager, Olympic Planning Unit

NSW Department of Health

\section{Tim Owen}

Public Health Officer,

NSW Public Health Officer Training Program

NSW Department of Health

NSW Health is responsible for providing public health services to support Olympic and Paralympic venues under
SOCOG's jurisdiction. These include:

- competition venues

- residential areas:

- athletes village

- Olympic 'Family' hotels mainly in the central business district of Sydney

- media village at Lidcombe

- youth camp at St Joseph's College at Hunters Hill 
- SOCOG medical centres and the SOCOG Polyclinic at Homebush Bay.

To manage and coordinate the public health issues arising at these venues, a 'virtual' public health unit will be established, composed of individuals performing functions from a number of locations. This Olympic-Paralympic Public Health Unit will:

- provide expert public health advice to SOCOG medical personnel

- act as a central point of notification of scheduled medical conditions diagnosed at SOCOG medical centres or the Polyclinic

- conduct investigation of disease clusters at venues

- conduct public health follow-up, where necessary

- provide liaison between NSW Health, SOCOG, local public health units, and other key parties.

The Olympic-Paralympic Public Health Unit will operate from the day the Olympic village opens, through to the end of the Olympic Games, and again during the period of the Paralympic Games. During the Olympic Games period, the Unit's staff will consist of a surveillance manager, surveillance officer, food safety coordinator, environmental health coordinator, medical epidemiologist, public health nurse and public health officer, and teams of food inspectors and environmental health officers. During the Paralympic Games a smaller number of competitors, officials, and spectators are expected, and most will be based at Sydney Olympic Park. For this reason, fewer staff will operate the Olympic-Paralympic Public Health Unit during this period.

A Public Health Investigation Team will also be formed as a back-up resource for deployment in the event of a public health investigation requiring resources beyond those of the Olympic-Paralympic Public Health Unit. This Public Health Investigation Team will consist of additional food inspectors, environmental health officers, public health nurses and a public health officer. As well as providing support to the Olympic-Paralympic Public Health Unit, the Public Health Investigation Team will provide other support as determined by the Public Health Controller under the NSW HEALTHPLAN counter disaster plan.

In order to minimise disruptions to the metropolitan public health units that are already heavily involved in Olympic activities, many of the staff for the Olympic-Paralympic Public Health Unit and the Public Health Investigation Teams have been drawn from rural public health units and the NSW Public Health Officer Training Program.

The establishment of an Olympic-Paralympic Public Health Unit will ensure that comprehensive and coordinated public health services are available to those people residing in or attending events at venues under SOCOG's jurisdiction.

\section{PUBLIC HEALTH PLANNING FOR THE SYDNEY 2000 OLYMPIC AND PARALYMPIC GAMES IN METROPOLITAN AREA HEALTH SERVICES}

\section{Catherine Bennett}

Northern Sydney Public Health Unit

\section{Mark Bartlett}

Western Sector Public Health Unit

\section{Graham Burgess}

Central Sydney Public Health Unit

\section{Brian Spooner}

South Eastern Sydney Public Health Unit

In addition to an increase in visitors to Sydney and movement to and from Olympic venues, many activities and attractions are planned throughout the Sydney metropolitan area for the period of the Sydney 2000 Olympic and Paralympic Games. Public health planning and strategy development has been conducted at the NSW Department of Health, area health service, public health unit, and local government levels to ensure that all possible steps have been taken to mitigate public health risk.
This article outlines the direction taken by metropolitan public health units in the lead up to the Games and the roles and responsibilities of the metropolitan public health units' Olympic Public Health Coordinators.

\section{PUBLIC HEALTH PLANNING}

Public health planning for risk reduction strategies and services for the Sydney 2000 Olympic and Paralympic Games began in 1996 with the formation of the NSW Department of Health Olympic Public Health Committee. In collaboration with the NSW Public Health Network (the 17 public health units and the Health Protection Branch of the NSW Department of Health), the Committee oversaw the development of several strategy documents, including the Public Health Service Strategy for the Sydney 2000 Olympic and Paralympic Games, ${ }^{1}$ and Public Health Unit Operational Issues for the Sydney 2000 Olympic Games-Public Health Protection 'Outside the Fence'. 